\title{
VALIDASI INSTRUMEN FOLLOWERSHIP MODEL KELLEY VERSI INDONESIA
}

\author{
Siti Asriyani Rosani, Medianta Tarigan \\ Departemen Psikologi, Universitas Pendidikan Indonesia \\ Email:asriyanirosa@gmail.com, medianta.tarigan@gmail.com
}

\begin{abstract}
This study aimed to describe the psychometric properties of the Followership measurement. The participants of the research were 377 of employees with range of 16 - 59 years old. The research used internal consistency of Alpha and construct validity with Confirmatory Factor Analysis (CFA), convergent validity, and discriminant validity. The results were high internal consistency reliability of Indonesian Kelly's followership styles ( $\alpha=0.882)$, and good fit indexes of modified two factor model (activity and independent), and finally showed the positive correlation to ledadership, work engagement, and religiosity measures.

Keywords: Kelley's Followership, Factorial, Convergent \& Discriminant Validity
\end{abstract}

\begin{abstract}
Abstrak
Penelitian ini bertujuan untuk menguji property psikometrik alat ukur Followership. Metode penelitian yang digunakan adalah penelitian kuantitatif dengan total sampel sebanyak 377 partisipan yang sudah bekerja dengan rentang usia 16 - 59 tahun. Teknik analisis data yang digunakan terdiri dari estimasi reliabilitas konsistensi internal dengan menggunakan formula Alpha serta uji validitasn konstruk menggunakan validitas faktorial dengan Confirmatory Factor Analysis (CFA), validitas konvergen dan diskriminan. Hasil yang diperoleh menunjukkan reliabilitas konsistensi internal yang tinggi $(\alpha=0.882)$. Sedangkan kecocokan CFA menunjukkan hasil yang fit setelah dilakukan modification indices dengan indeks ukuran kecocokan Root Mean Square of Approximation (RMSEA) sebesar 0.065 ( $\leq 0.08)$, Standarized Root Mean Residual (SRMR) sebesar $0.046(\leq 0.05)$, Goodness Fit Index (GFI) sebesar $0.901(\geq 0.90)$ dan Comparative Fit Index (CFI) sebesar 0.885 . Pendekatan validitas konvergen dan diskriminan dalam penelitian ini dilakukan dengan cara mengkorelasikan alat ukur Followership dengan alat ukur Ledadership, Work Engagement, dan Religiusitas.
\end{abstract}

Kata kunci: followership, reliabilitas, CFA, validitas konvergen dan diskriminan.

\section{PENDAHULUAN}

Individu-individu dalam sebuah organisasi memiliki peranannya masing-masing. Ada yang berperan sebagai pemimpin (leader) dan ada juga yang berperan sebagai pengikut (follower), atau bahkan seseorang mungkin memegang peran pemimpin dan 
pengikut pada saat yang bersamaan (Budiarto, 2005). Kepemimpinan sangat berkaitan dengan perilaku, baru kemudian menyangkut keahlian. Pemimpin yang baik diikuti oleh orang lain karena dia dipercaya dan dihormati, dibandingkan karena keahlian yang dimilikinya (Irawati, 2011). Pada era modern ini, harus ada peran yang lebih aktif dan sesuai dengan usaha dari kelompok atau tim, yaitu dibutuhkannya pengikut-pengikut yang aktif (Hoption, 2014). Selain itu, Warren Bennis, seorang ahli kepemimpinan, dalam artikel yang berjudul "The End of Leadership," mengatakan bahwa kepemimpinan yang efektif tidak mungkin ada tanpa keterlibatan, inisiatif, dan kerja sama dari para pengikutnya (Budiarto, 2005).

Semua pemimpin adalah pengikut, namun tidak semua pengikut adalah pemimpin. Pada dasarnya, setiap orang adalah pengikut, namun tidak setiap orang dapat menjadi pemimpin. Bagaimanapun, dalam sebuah organisasi pasti masih ada yang lebih tinggi lagi kedudukannya. Dengan kata lain, seorang pemimpin juga mengikuti orang lain, apapun posisi dari pimpinan tersebut (Budiarto, 2005). Leadership dan followership bagaikan dua sisi mata uang yang saling terkoneksi melalui interaksi keduanya (Yung \& Tsai, 2013). Followership adalah konsep yang menyertai serta melengkapi konsep leadership.

Followership adalah sebuah konsep penting yang sangat kurang mendapatkan perhatian, hal ini terjadi karena manusia cenderung melihat kepada tokoh figur apabila organisasi mengalami kemajuan (Burhanuddin, 2015). Kelley membagi gaya kepengikutan menjadi dua dimensi, yaitu: (a) independent, critical thinking dan dependent, uncritical thinking (berpikir kritis dan mandiri, dan berpikir tidak kritis dan tergantung); dan (b) aktif dan pasif (Montesino, 2003). Dimensi berpikir kritis dan mandiri meliputi individu yang berpikir dengan dirinya sendiri, memberi kritik yang membangun, menjadi diri sendiri, serta inovatif dan kreatif. Sedangkan untuk berpikir tidak kritis dan tergantung adalah kebalikan dari pemikiran kritis dan mandiri, yaitu harus diperintah terlebih dahulu untuk melakukan tugas, tidak dapat mengurus diri sendiri, dan tidak berpikir secara kritis. Dalam dimensi aktif dan pasif, pengikut yang baik adalah individu yang mengambil inisiatif, memiliki rasa kepemilikan terhadap kelompok atau tim kerja, berpartisipasi secara aktif, memulai semuanya dari diri sendiri, dan pekerja keras. Sebaliknya, pengikut yang tidak baik adalah individu yang malas, pasif, selalu membutuhkan dorongan, membutuhkan pengawasan terus-menerus, dan menghindari tanggung jawab (Budiarto, 2005).

Blanchard, dkk (2009) melakukan penelitian mengenai validitas alat ukur followership yang pertama kali dicetuskan oleh Robert Kelley pada tahun 1992 dengan menggunakan metode Explaratory Factor Analysis, dengan hasil terdapat tiga faktor pada alat ukur tersebut. Dua faktor mempunyai nama yang sama dengan faktor yang digagas oleh Kelley yaitu faktor critical thinking dan active engagement. Sedangkan faktor lainnya diberi nama attitude and affect. Pada penelitian ini item-item yang termasuk kedalam faktor attitude and affect dieliminasi karena tidak merepresentasikan 
follower behavior. Kemudian, faktor critical thinking dan active engagement dikorelasikan dan hasilnya rendah yaitu $\mathrm{r}=0.33$. Follower dengan active engagement rendah mempunyai kepuasan kerja yang rendah pula meski mempunyai level critical thinking yang tinggi. Sedangkan follower dengan active engagement dan independent critical thinking yang tinggi mempunyai nilai kepuasan intrinsik yang paling tinggi. Dari dua dimensi critical thinking dan active engagement menghasilkan beberapa gaya pengikut yaitu efektif atau exemplary, konformis, pasif, dan alienated (Kelley, 1988)

Efektif: pengikut yang kritis, mandiri, dan aktif dalam perilakunya. Mereka menunjukkan perilaku yang konsisten kepada semua orang, terlepas dari kekuatan mereka dalam organisasi, dan menangani konflik dan risiko dengan baik. Mereka menghadapi perubahan, mengedepankan pandangan mereka sendiri, dan tetap fokus pada apa yang dibutuhkan organisasi. Mereka mengerti bagaimana orang lain melihat mereka - jadi penuh perhatian. Mereka sering melakukan tindakan kepemimpinan, dan sering menggunakan referensi, pakar, jaringan, dan kekuatan informasi mereka untuk melayani organisasi. Kelly menyebut grup ini "The Stars" (Kelley, 1988).

Konformis: tipe pengikut ini sangat sibuk, tetapi tidak harus melibatkan otak mereka untuk memikirkan apa yang sedang mereka lakukan. Mereka berpartisipasi dengan sangat sukarela tetapi tidak mempertanyakan pesanan. Mereka akan menghindari konflik dengan segala cara dan mengambil jalan yang paling sunyi, tetapi akan membela bos mereka sampai ekstrem yang setia. Kelley memberi nama tipe pengikut ini "The Yes-People" (Kelley, 1988).

Pasif: pikirkan tentang seorang anak berusia dua tahun yang tidak ingin melakukan sesuatu dan hanya gagal. Ini adalah pengikut pasif. Mereka tidak cukup melibatkan otak mereka, juga tidak melakukan tindakan nyata. Robert Kelley menyebut grup ini "The Sheep". Meskipun tidak menunjukkan inisiatif atau tanggung jawab apa pun, tipe pengikut ini bisa merupakan hasil dari manajer mikro atau budaya negatif, terlalu mengendalikan, dan berorientasi pada kesalahan (Kelley, 1988).

Alienated: pengikut ini berpikir sangat baik, tetapi karena alasan tertentu sering kali menyergap dari sela-sela. Mereka terjebak di tempat mereka berada, sangat negatif dan merasa kehilangan kekuatan. Mereka telah melihat 'terlalu banyak', menjadi pahit dalam pekerjaan mereka karena tidak berkesempatan untuk promosi, atau karena telah tinggal terlalu lama di satu posisi (Kelley, 1988).

Pragmatic Survivor: tipe pengikut ini yang saya anggap sebagai 'kenari di poros tambang' organisasi. Mereka dapat beralih di antara gaya pengikut yang berbeda, untuk menyesuaikan dengan setiap situasi, dan merupakan sistem peringatan dini kami ketika budaya organisasi mulai berubah menjadi lebih buruk. Kita semua tahu bahwa ada beberapa orang yang dapat melihat tulisan di dinding lebih awal: mengidentifikasi mereka dan menggunakannya untuk memastikan bahwa budaya kerja Anda tetap sehat setiap saat (Kelley, 1988). 
Penelitian mengenai konsep followership di Indonesia dapat dikatakan masih sangat sedikit. Peneliti menemukan satu buah karya tulis setingkat Thesis karya Burhanuddin (2015). Hasil dari penelitian tersebut menyatakan bahwa dimensi active engagement memberikan pengaruh yang positif terhadap semua variabel yang diujikan yaitu komitmen organisasi, kepuasan kerja dan Organizational Citizen Behavior (OCB). Sedangkan dimensi independent critical thinking memberikan pengaruh yang negatif terhadap beberapa dimensi dari variabel dependen. Burhanuddin (2015) mereplikasi penelitian dari Blanchard (2009) dengan menambahkan variabel Organizational Citizens Behavior (OCB) pada penelitiannya dan menganalisis reliabilitas 20 item alat ukur followerhip dari Kelley yang menghasilkan alpha 0.778 .

Sejauh ini penelitian psikometri mengenai followership yang dapat ditemukan adalah penelitian yang dilakukan oleh Blanchard dkk. (2009) yang melakukan analisis faktorial pada alat ukur followership yang digagas oleh Kelley (1992) dengan menggunakan metode Exploratory Factor Analysis (EFA). Di Indonesia sendiri belum terdapat penelitian psikometri mengenai alat ukur followership, maka dari itu peneliti akan melakukan analisis faktorial dengan menggunakan metode Confirmatory Factor Analysis (CFA). Selain validasi konstruk faktorial, peneliti juga akan menguji alat ukur followership dengan variabel Work Engagement, Transformational Leadership, Transactional Leadership, dan Religiusitas.

\section{METODE}

Penelitian ini menggunakan pendekatan kuantitatif dengan pendekatan cross sectional, yaitu rancangan penelitian dengan melakukan pengukuran atau pengamatan pada saat bersamaan atau sekali waktu (Hidayat, 2007). Jumlah partisipan yang terlibat dalam penelitian ini sebanyak 377 partisipan yang sudah bekerja pada perusahaan atau organisasi yang menghasilkan benefit.

Instrumen penelitian yang digunakan yakni instrumen Followership Styles (Kelley, 1992) untuk mengukur followership, Multifactor Leadership Questionnaire (MLQ) (Bass \& Avolio, 1997) untuk mengukur Transformational Leadership \& Transactional Leadership, Utretch Work Engagement Scale (UWES) (Titien, 2016) dan skala Religiusitas (Purnomo \& Suryadi, 2017) untuk mengukur religiusitas.

\section{HASIL}

Reliabilitas instrumen followership ini memiliki reliabilitas yang tinggi baik untuk seluruh item maupun perdimensi. Instrumen Followership dengan 20 item memiliki 
reliabilitas 0,883 , sedangkan untuk dimensi critical thinking memiliki reliabilitas sebesar 0,771, dan dimensi active engagement memiliki reliabilitas sebesar 0,833.

Tabel 1 menunjukkan nilai indeks kecocokan dari alat ukur Followership sebelum dan setelah dilakukan modification indices. Hasil perhitungan CFA pada analisis model awal termasuk kurang fit jika dilihat dari beberapa parameternya. RMSEA untuk model yang dapat dikatakan fit seharusnya mempunyai nilai $\leq 0.08$, model yang fit seharusnya mempunyai nilai SRMR $\leq 0.05$. Nilai GFI dan CFI $\geq 0.9$ (Hooper et al., 2008; Hair et al., 2014). Muatan faktor pada masing-masing item pada alat ukur Followership ini berkisar antara 0.24 sampai 0.67. Peneliti melakukan Modification Indices yang merupakan salah satu metode dalam CFA untuk meningkatkan indeks fit pada suatu model (Furr \& Bacharach, 2014). Modification indices yang dilakukan peneliti adalah melakukan korelasi antar error sampai diperoleh model yang fit.

Tabel 1

Fit Index Model Dua Faktor Followership Versi Indonesia

\begin{tabular}{llll}
\hline \multirow{2}{*}{ Indeks Kecocokan Model } & \multicolumn{3}{c}{ Nilai Indeks } \\
\cline { 2 - 4 } & Model Awal & Model Modifikasi & 3 Faktor \\
\hline Root Means Square Error of Approximation (RMSEA) & 0.086 & 0.065 & 0,062 \\
Standarized Root Mean Residual (SRMR) & 0.061 & 0.046 & 0,047 \\
Goodness Fit Index (GFI) & 0.841 & 0.901 & 0,918 \\
Comparative Fit Index (CFI) & 0.786 & 0.885 & 0,903 \\
\hline
\end{tabular}

Tabel 2

Muatan Faktor Followership Versi Indonesia

\begin{tabular}{llllll}
\hline Dimensi & Item & Muatan Faktor & Dimensi & Item & Muatan Faktor \\
\hline & Item 1 & 0.62 & & Item 2 & 0.54 \\
& Item 5 & 0.50 & Item 3 & 0.58 \\
Item 11 & 0.67 & Item 4 & 0.57 \\
Indepen- & Item 12 & 0.51 & Item 6 & 0.67 \\
dent Critical Thinking & Item 14 & 0.43 & Active & Item 7 & 0.54 \\
& Item 16 & 0.53 & Item 8 & 0.45 \\
& Item 17 & 0.47 & Item 9 & 0.49 \\
& Item 18 & 0.37 & Item 10 & 0.63 \\
& Item 19 & 0.24 & Item 13 & 0.60 \\
& Item 20 & 0.33 & Item 15 & 0.59 \\
\hline
\end{tabular}

Hasil perhitungan analisis CFA setelah dilakukan modification indices menunjukkan nilai indeks kecocokan absolut model yang baik antara model dengan data yang diperoleh. Indikator yang menjadi acuan bahwa analisis CFA menunjukkan kecocokan model yang baik diantaranya nilai RMSEA sebesar 0.065 , nilai SRMR sebesar 0.046 nilai GFI sebesar 0.901 serta nilai CFI sebesar 0.885 yang mana seluruh parameter yang digunakan peneliti untuk menganalisis faktor alat ukur Followership telah sesuai dengan kriteria minimum nilai indeks kecocokan suatu model. Sementara itu, model tiga faktor (Independent Critical Thinking, Attitude \& Affect, Active Engagement) yang mengikuti model Balncard (2009) adalah model terbaik dalam indeks kecocokan yang 
mana semua indeks menunjukkan indeks yang signfikan yaitu RMSEA $=0,062(0,02 \leq$ $0,08), \operatorname{RMSR}=0,047(\leq 0,05), \mathrm{GFI}=0,918(0,90 \leq)$, dan CFI $=0,901(0,90 \leq)$.

Tabel 4

Korelasi Followership Versi Indonesia dengan Variabel Kriteria

\begin{tabular}{cccc}
\hline Alat Ukur & Dimensi & Independent Critical Thinking & Active \\
\hline \multirow{5}{*}{ Leadership } & Idealized Influence & 0.582 & 0.501 \\
& Inspirational Motivation & 0.640 & 0.588 \\
& Intellectual Stimulation & 0.618 & 0.598 \\
& Individual Consideration & 0.576 & 0.524 \\
& Contingent Reward & 0.624 & 0.498 \\
& Management by Exception & 0.479 & 0.455 \\
& Laizes-Faire & 0.394 & 0.414 \\
\hline \multirow{3}{*}{ Work Engagement } & Vigor & 0.589 & 0.415 \\
& Dedication & 0.567 & 0.369 \\
& Absorption & 0.633 & 0.433 \\
\hline \multirow{5}{*}{ Religiusitas } & Intellectual & 0.153 & 0.157 \\
& Ideology & 0.074 & 0.029 \\
& Public Practice & 0.222 & 0.125 \\
& Private Practice & 0.223 & 0.193 \\
& Religious by Experience & 0.335 & 0.279 \\
\hline
\end{tabular}

Sedangkan hasil korelasi dimensi Active yang ada pada alat ukur Followership dan alat ukur Leadership, Work Engaagement, dan Religiusitas. Untuk korelasi pada dimensi Active dengan Transformational Leadership secara keseluruhan mempunyai korelasi yang cukup kuat ( $\mathrm{r}>0.5$ ). Sebaliknya, hasil korelasi dimensi Active dengan Transactional Leadership mempunyai hasil korelasi yang tidak terlalu kuat $(\mathrm{r}<0.5)$.

Tabel 4 memperlihatkan hasil korelasi model dua faktor alat ukur Followership dan alat ukur Leadership, Work Engaagement, dan Religiusitas. Untuk korelasi pada dimensi Independent Critical Thinking dengan Transformational Leadership secara keseluruhan mempunyai korelasi yang cukup kuat ( $\mathrm{r}>0.5)$. Sebaliknya, hasil korelasi dimensi Independent Critical Thinking dengan Transactional Leadership mempunyai hasil korelasi yang tidak terlalu kuat $(\mathrm{r}<0.5)$.

Secara keseluruhan, hasil korelasi dimensi Independent Critical Thinking dengan dimensi Vigor, Dedication dan Absorption mempunyai korelasi yang cukup kuat ( $\mathrm{r}=>$ 0.5). Sedangkan hasil korelasi pada dimensi Independent Critical Thinking dengan dimensi-dimensi alat ukur Religiusitas mempunyai hasil yang lemah sampai hampir tidak ada korelasi antar dimensinya yang ditandai oleh hasil korelasi dimensi dengan rentang $0.335-0.074$.

Hasil korelasi dimensi Independent Critical Thinking dengan dimensi Vigor, Dedication dan Absorption mempunyai korelasi yang tidak telalu kuat $(\mathrm{r}=<0.5)$. Hasil korelasi pada dimensi Active dengan dimensi-dimensi alat ukur Religiusitas mempunyai 
hasil yang lemah sampai hampir tidak ada korelasi antar dimensinya, yang ditandai oleh hasil korelasi dengan rentang 0.279 - 0.029 .

\section{PEMBAHASAN}

Reliabilitas alat ukur followership dengan seluruh item 0,882 relatif setara dengan reliabilitas followership versi asal atau dalam bahasa Inggris yaitu 0,89 (Novikov, 2016). Untuk dimensi berfikir kritis $(0,771)$ juga relatif sama dengan penelitianpenelitian sebelumnnya yaitu rentang 0,63 sampai 0,74 sedangkan dimensi keterlibatan aktif $(0,833)$ juga relatif sama dengan penelitian lain yang memiliki rentang 0,69-0,87 (Nejad, Naami, Beshlideh, 2015). Hasil ini menunjukkan bahwa alat ukur yang dikembangkan di Indonesia ini relatif bagus secara reliabilitas sehingga sangat bisa diandalkan untuk digunakan sebagai alat ukur dalam penelitian tentang followership di masa yang akan datang.

Model dua faktor asli dan model dua faktor modifikasi indeks untuk alat Followership ini memang kurang memuaskan. Dengan demikian, model penelitian ini tidak bisa memenuhi model dua faktor Kelley (1998) yaitu Critical Independent dan Active Engagement. Dalam hal ini model faktor lain dipertimbangkan untuk diajukan sebagai model untuk diuji dengan CFA. Misal model tiga faktor yang ditemukan signifikan oleh Blanchard (2009) atau model tiga faktor (Ligon dkk., 2019). Model tiga faktor Blanchard (2009) ternyata lebih layak untuk data yang diambil di Indonesia sehingga memaknai followership Indonesia lebih tepat dengan konsep Blanchard daripada Kelley. Alaternatif lain untuk menguji model faktor followership Indonesia adalah melakukan Analisis Faktor Eksploratori (EFA) sehingga akan ditemukan model baru bagi alat ukur followership ini.

Korelasi followership Indonesia dengan berbagai variabel lain juga menunjukkan hasil yang sama dengan penelitian-penelitian lain. Followership berkorelasi positif dengan work engagement dan kepemimpinan. Karyawan yang kritis akan cenderung terikat dengan pekerjaannya, demikian juga karyawan yang aktif juga akan cenderung terikat dengan pekerjaan. Ligon, dkk., (2019) menemukan bahwa gaya pengikut exemplary berkorelasi positif dengan work engagement (keterikatan kerja). Gaya pengikut exemplary (teladan) adalah pengikut independen, pemikir kritis, inovatif dan mau mempertanyakan kepemimpinan. Pengikut teladan memiliki tingkat tinggi di dimensi independen dan pemikiran kritis dan keterlibatan aktif. Tipe pengikut ini sangat penting untuk keberhasilan organisasi karena gaya pengikut ini sangat ideal dalam banyak hal. Pengikut teladan mempertimbangkan konsekuensi tugas sebelum mereka melaksanakannya dan unggul dalam semua tugas. Mereka memperlakukan semua orang di organisasi dengan cara yang sama, bergaul dengan sangat baik dengan rekan-rekan mereka (Bjugstad et al., 2006), memberikan dukungan dan kritik cerdas kepada pemimpin dan bahkan menarik dukungan mereka dari pemimpin yang tidak kompeten 
tanpa mengganggu operasi organisasi. Mereka berdiri untuk melayani kepentingan terbaik organisasi. Pengikut teladan cenderung berfungsi dengan sangat baik di tim yang dikelola sendiri. Mereka adalah aset terbaik manajer dalam arti bahwa mereka melengkapi upaya para pemimpin dan dapat diandalkan untuk membebaskan pemimpin dari banyak tugas (Mushonga \& Torrance, 2008). Sekalipun dalam penelitian ini tidak menentukan gaya kepengikutan tetapi semua dimensi kepengikutan juga menghasilkan korelasi yang sama yaitu positif.

Berdasarkan analisis data dan pembahasan yang telah diuraikan sebelumnya, kesimpulan yang dapat diperoleh dari penelitian ini adalah: a) Alat ukur Followership dengan total item sebanyak 20 item yang digunakan peneliti adalah alat ukur yang reliabel karena mempunyai nilai koefisien reliabilitas yang tinggi baik pada keseluruhan item, maupun pada setiap dimensinya. b) Validitas faktorial model dua faktor alat ukur Followership yang diuji dengan menggunakan analisis Confirmatory Factor Analysis merupakan model alat ukur yang dapat diterima oleh teori jika dilakukan modification indices dengan mengkorelasikan nilai error yang telah direkomendasikan. c) Validitas konvergen antara alat ukur Followership dengan alat ukur Leadership dan Work Engagement menunjukkan adanya korelasi yang moderat yang menunjukkan adanya hubungan antara alat ukur tersebut.

\section{DAFTAR PUSTAKA}

Azwar, Saifuddin. (2015). Dasar-Dasar Psikometri. Yogyakarta: Pustaka Pelajar

Azwar, Saifuddin. (2016). Reliabilitas dan Validitas. Yogyakarta: Pustaka Pelajar

Azwar, Saifuddin. (2016). Tes Prestasi. Yogyakarta: Pustaka Pelajar

Blanchard, Anita L. dkk.. (2009). Followership Styles and Employee Attachment to the Organization. The Psychologist-Manager Journal, 12 (1), 111-131.

Budiarto, Yohanes. (2005). Followership: Sisi Lain Kepemimpinan yang Terlupakan. Jurnal Psikologi, 3 (1), 19-23.

Budiharto, S. (2006). Konstruk Teoritis dan Pengukuran Kepemimpinan Profetik. Jurnal Psikologi, 33(2), 133-145.

Burhanuddin, Adi. (2015). Pengaruh terhadap Komitmen Organisasi, Kepuasan Kerja, dan Organizational Citizen Behavioral. (Tesis). Program Magister Sains Program Studi Psikologi Industri dan Organisasi, Universitas Indonesia, Jakarta.

Cook, D. A., \& Beckman, T. J. (2006). Current Concepts in Validity and Reliability for Psychometric Instruments: Theory and Application. The American Journal of Medicine, 119(2), 166.e7-166.e16. https://doi.org/10.1016/j.amjmed.2005.10.036 
Golafshani, N. (2003). Understanding Reliability and Validity in Qualitative Research. The Qualitative Report, 8(4), 597-606.

Hair, J.F. JR., Anderson, R.E, Tatham, R.L. \& Black, W.C. (2014). Multivariate Data Analysis. Ten Edition. New Jersey: Pearson Educational, Inc

Haynes, S. N., Richard, D. C. S., \& Kubany, E. S. (1995). Content Validity in Psychological Assessment: A Functional Approach to Concepts and Methods. Psychological Assessment, 7(3), 238-247.

Hooper et al. (2008). Structural Equation Modelling: Guidelines for Determining Model Fit. Electronic Journal of Business Research Methods. 6 (1), 53 - 60

Hoption, Colette. (2014). Learning and Developing Followership. Journal of Leadership Education, 13 (1), 129-137.

Irawati, Dwi. (2011). Perkembangan Teori Kepemimpinan: Suatu Tinjauan Pustaka. SEGMEN Jurnal Manajemen dan Bisnis, 1 (1), 17-30.

Kelley, R (1988) In Praise of Followership. Leadership Magazine Article, Harvard Bussines Review. Diakses dari: https://hbr.org/1988/11/in-praise-of-followers

Lunenburg, Fred C. (2011). Leadership versus Management: A Key Distinction - At Least in Theory. International Journal Of Management, Business, And Administration, 14(1)

Matondang, Z. (2009). Validitas dan reliabilitas suatu instrumen penelitian. Jurnal Tabularasa PPS UNIMED, 6(1), 87-97.

Montesino, M., Leadership/Followership Similarities between People in A Developed and A Developing Country: The case of Dominicans in NYC and Dominicans on the Island. Journal of Leadership and Organizational Studies, 10 (1), 82-92.

Munawaroh. (2011). Pengaruh Gaya Kepemimpinan Transformasional dan Transaksional terhadap Kinerja Guru. Jurnal Ekonomi Bisnis, 16(2), 136-144.

Novitasari, P., \& Satriyo, B. (2016). Pengaruh gaya kepemimpinan transformasional dan motivasi kerja terhadap kinerja karyawan. Jurnal Ilmu Riset Manajemen, 5(September), 1-20.

Rahayuningsih, T. (2014). Kepemimpinan Profetik , Budaya Organisasi, dan Komitmen Prophetic Leadership , Organizational Culture, and Organizational Commitment on Universitas Abdurrab's Employees. Jurnal Psikologi, 12(2), 117121.

Tavakol, M., \& Dennick, R. (2011). Making sense of Cronbach's alpha. International Journal of Medical Education, 2, 53-55. https://doi.org/10.5116/ijme.4dfb.8dfd 
Thanasegaran, G. (2003). Reliability and Validity Issues in Research. Integration \& Dissemination.

Thompson, N. A. (2013). Reliability \& Validity. USA: Assessment System.

Vanvoorhis, C. R. W., \& Morgan, B. L. (2007). Understanding Power and Rules of Thumb for Determining Sample Sizes. Psi Chi Journal of Undergraduate Research, $3(2), 43-50$.

Oyetunji, Christianah O. (2013). The Relationship between Followership Style and Job Ferformance in Botswana Private Universities. International Education Studies, 6 (2), 179-187.

Yung, Chen Tsun \& Tsai, Kuan Chen. (2013). Followership: An Important Partner of Leadership. Bussiness and Management Horizons, 1 (2), 47-55. 